\title{
SYNTHESIS OF INDOLE, COUMARINYL AND PYRIDINYL DERIVATIVES OF ISONIAZID AS POTENT ANTITUBERCULAR AND ANTIMICROBIAL AGENTS AND THEIR MOLECULAR DOCKING STUDIES
}

\author{
ANIL S. RATHOD, SHIVAKUMAR S. GODIPURGE, JAIPRAKASH S. BIRADAR* \\ Department of Chemistry, Gulbarga University, Kalaburagi 585106 \\ Email: jsbiradar55@gmail.com
}

Received: 11 Aug 2017 Revised and Accepted: 02 Nov 2017

\begin{abstract}
Objective: The aim of this study was to the synthesis of indole, coumarinyl and pyridinyl derivatives of isoniazid as potent anti-TB and antimicrobial agents and their molecular docking studies.

Methods: The structures of the newly synthesized compounds were confirmed by FT-IR, ${ }^{1} \mathrm{HNMR}$, and Mass spectroscopic methods and to evaluate the biological studies like anti-TB, antimicrobial and antioxidant activities. The mode of action of these active compounds was carried out by molecular docking studies.

Results: Among all the synthesized compounds tested $5 \mathrm{~d}$ was found to be the most active with $M$. tuberculosis $\mathrm{H}_{37} \mathrm{Rv}$ strain at $12.5 \mu \mathrm{g} / \mathrm{ml}, 5 \mathrm{~b}$ at $25 \mu \mathrm{g} / \mathrm{ml}, 4 \mathrm{~d}$ was found to be the most active with S. typhi, S. aureus and A. Nizer, 5a with A. Oryzae, 5c with A. terrous and A. Flavous and 5d with Shegella at $100 \mu \mathrm{g} / \mathrm{ml}$ and some of the compounds like $4 \mathrm{~d}, 5 \mathrm{a}, 5 \mathrm{~b}$ and $5 \mathrm{~d}$ have shown promising antioxidant properties.
\end{abstract}

Conclusion: All the synthesized compounds have exhibited promising anti-TB, antimicrobial and antioxidant activities.

Keywords: Indole, Coumarin, Isonicotinic acid hydrazide(INH), Pyrazole, M. tuberculosis, Antimicrobial, Antioxidant activities and Molecular docking studies

(C) 2017 The Authors. Published by Innovare Academic Sciences Pvt Ltd. This is an open access article under the CC BY license (http://creativecommons.org/licenses/by/4.0/) DOI: http://dx.doi.org/10.22159/ijpps.2017v9i12.21970

\section{INTRODUCTION}

Tuberculosis (TB) is still a challenging worldwide health problem and M. tuberculosis remains one of the single most deadly human pathogens. The resurgence of TB over the last two decades, even in industrialized countries where it was almost eradicated has been favoured by the pathogenic synergy with human immune deficiency virus (HIV) infection. In fact, TB and other typical mycobacteriosis are now diseased frequently associated with AIDS; HIV infection significantly increases the risk that new or latent TB infections will progress to active diseases [1-3]. The emergence of TB has also been accompanied by the appearance of single-drug-resistant (SDR) and multidrug-resistant (MDR) strains of M. tuberculosis which are insensitive to one or more of the first-line anti-TB drugs like isoniazid (INH), rifampin (RFM), ethambutol (EMB), streptomycin (SPM) and pyrazinamide (PZA) [4]. Indeed, a great amount of work has been done in order to acquire useful knowledge about the mechanisms of action and resistance to available anti-TB drugs [5]. The primary mechanism of MRD in TB is the accumulation of mutations in individual drug target genes [6]. In fact, currently, combinations of two or more antiTB drugs are used to prevent the development of resistant mycobacteria, sometimes it is also necessary to resort to second-line drugs ciprofloxacin(CFX), ethionamide (EMD), kanamycin(KNM), aminosalicylic acid(ASA), etc [7-8]. Living organisms find difficulty in construction of $\mathrm{N}-\mathrm{N}$ bonds which limits the natural abundance of compounds having such bonds. Pyrazole and their derivatives, a class of compounds containing the $\mathrm{N}-\mathrm{N}$ bond exhibits a wide range of biological activities [9-14]. Much attention is given to pyrazoles as antimicrobial agents after the discovery of natural pyrazole Cglycoside like pyrazofurin (PZF) which demonstrated a broad spectrum antimicrobial activity [15]. A literature survey has revealed that pyrazole derivatives are active against many mycobacteria [1617]. Among the standard antimycobacterial agents, INH is still considered to be a first line drug for chemotherapy of TB. It has very high in vivo inhibitory activity against M. tuberculosis $\mathrm{H}_{37} \mathrm{Rv}$ strain. Enzymatic acetylation of INH by $\mathrm{N}$-acetyltransferase represents a major metabolic pathway for INH in human beings. Acetylation greatly reduces the therapeutic activity of the drug, resulting in underdosing, decreased bioavailability, and acquired INH resistance [18]. Chemical modification of INH with a functional group that blocks acetylation, while maintaining a strong antimycobacterial action, may improve clinical outcomes and facilitate to reduce the rise of INH resistance. In modern drug designing, molecular docking is routinely used for understanding drug-receptor interaction. This method has been frequently used to predict the binding affinity and orientation of small drug molecules at the active site of their protein targets and to rationalize the selectivity observed. This study was performed with Tripos SYBYL X 2.2.1. Program which was based on docking procedure and validated on the basis of reference compounds from the literature data. Due to the remarkable importance of pyrazole derivatives, the aim of this article was to synthesise an indole, coumarinyl, pyridinyl and INH derivatives as potent anti-TB and antimicrobial agents and their molecular docking studies.

\section{MATERIALS AND METHODS}

General

All chemicals used in this research were purchased from sigma Aldrich and SD Fine chemicals. Melting points were taken in open capillary tubes and are uncorrected. The purity of the compounds was checked by thin layer chromatography using Merck silica gel 60 F254 coated aluminum plates. IR spectra were recorded on Shimadzu-FTIR Infrared spectrometer in $\mathrm{KBr}$ pellets $(100 \mathrm{mg}) .{ }^{1} \mathrm{HNMR}$ spectra were recorded on a Bruker (400 MHz) tetramethylsilane (TMS) as an internal standard. LCMS were obtained using Agilent 1200 series Mass spectrometer (SAIF) Punjab.

\section{Experimental part}

General procedure

Protocol for the synthesis of Starting materials

Starting material 2,5-disubstituted-1H-indol-3-carboxaldehyde(1) were prepared by literature method [22] and 3-acetyl-2H-chromen2-one(2) was the literature procedure [23]. 


\section{General procedure for the preparation of chalcones $3(\mathrm{a}-\mathrm{d})$}

2,5-disubstituted indole-3-carboxaldehyde $(0.01 \mathrm{~mol})$ and 3 acetylcoumarin $(0.01 \mathrm{~mol})$ in $\mathrm{n}$-butanol $(30 \mathrm{ml})$ was added to piperidine $(1 \mathrm{ml})$. The mixture was refluxed for $4 \mathrm{~h}$. It was poured into crushed ice and acidified with diluted $\mathrm{HCl}$. The product obtained was filtered, washed with water and recrystallized from ethanol [21].

\section{Synthesis of dibromo derivative of chalcones 4(a-d)}

To a solution of chalcones $3(\mathrm{a}-\mathrm{d})(0.1 \mathrm{~mol})$ in chloroform $(10 \mathrm{ml})$, bromine $(0.125 \mathrm{~mol})$ chloroform $(10 \mathrm{ml})$ was added slowly with stirring at $0{ }^{\circ} \mathrm{C}$. After completion of the addition of the bromine solution, the reaction mixture was stirred for $5 \mathrm{~h}$. The solid obtained was filtered and recrystallized with a suitable solvent.

\section{Synthesis of pyrazoles $5(a-d)$}

A mixture of dibromo derivative of chalcones $4(\mathrm{a}-\mathrm{d})(0.01 \mathrm{~mol}), \mathrm{INH}$ $(0.012 \mathrm{~mol})$ and triethylamine $(3 \mathrm{ml})$ was heated under reflux in absolute ethanol $(15 \mathrm{ml})$ for $8 \mathrm{~h}$. The reaction mixture was cooled and poured into ice cold water. The solid separated was filtered, dried and recrystallized from ethanol.
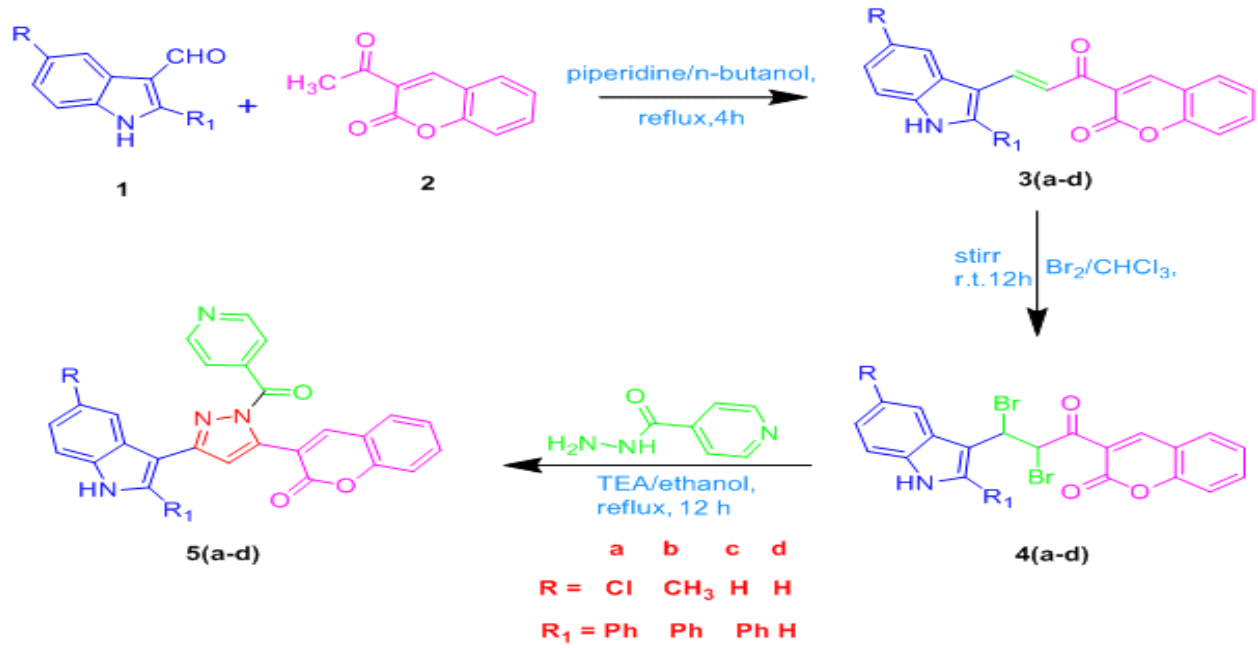

Scheme

\section{Spectral analysis of synthesized compounds}

3-(2, 3-dibromo-3-(5-chloro-2-phenyl-1H-indol-3-yl) propanoyl) 2H-chromen-2-one(4a)

Brownish crystals, $\mathrm{MP}=155-156{ }^{\circ} \mathrm{C}$, yield; $60 \%$, IR $\left(\mathrm{KBr}, \mathrm{cm}^{-1}\right)$ 3231( $\mathrm{NH}$ ), 3032( $\mathrm{Ar}-\mathrm{H}), 1665$ ( $\mathrm{C}=0$ of lactone), 1607 (C=0 of amide), $1249(-0-), 696(\mathrm{C}-\mathrm{Br})$ and $669 \mathrm{~cm}^{-1}(\mathrm{C}-\mathrm{Cl}) .{ }^{1} \mathrm{H}$ NMR $(400 \mathrm{MHz}, \delta$ ppm) (DMSO-d 6 ), $10.7(\mathrm{~s}, 1 \mathrm{H}, \mathrm{NH}), 7.5-8.5(\mathrm{~m}, 13 \mathrm{H}, \mathrm{Ar}-\mathrm{H}), 5.09(\alpha-\mathrm{H})$ and $5.32(\beta-\mathrm{H})(\mathrm{d}, 2 \mathrm{H}, \mathrm{CHBr})$

3-(2, 3-dibromo-3-(5-methyl-2-phenyl-1H-indol-3-yl) propanoyl)2H-chromen-2-one(4b)

Brownish crystals, $\mathrm{MP}=162-163^{\circ} \mathrm{C}$, yield; $50 \%$, IR $\left(\mathrm{KBr}, \mathrm{cm}^{-1}\right) ; 3397$ $(\mathrm{NH}), 2885-2950\left(\mathrm{C}-\mathrm{H}_{1} \mathrm{CH}_{3}\right), 1657$ ( $\mathrm{C}=0$ of lactone), 1602 ( $\mathrm{C}=0$ of amide), 1243 (-0-) and $685(\mathrm{C}-\mathrm{Br}) .{ }^{1} \mathrm{H}$ NMR $(400 \mathrm{MHz}, \delta \mathrm{ppm})$ (DMSO-d $\left.\mathrm{d}^{6}\right), 11.2(\mathrm{~s}, 1 \mathrm{H}, \mathrm{NH}), 7.2-8.2(\mathrm{~m}, 13 \mathrm{H}, \mathrm{Ar}-\mathrm{H}), 5.09(\alpha-\mathrm{H})$ and $5.32(\beta-\mathrm{H})(\mathrm{d}, 2 \mathrm{H}, \mathrm{CHBr}) .2 .5\left(\mathrm{~s}, 3 \mathrm{H}, \mathrm{CH}_{3}\right)$. Mass; LCMS $(\mathrm{m} / \mathrm{z})$ $=562(\mathrm{M}+\cdot),(\mathrm{m} / \mathrm{z})=564\left(\mathrm{M}^{+}+2\right)$ and $(\mathrm{m} / \mathrm{z})=566\left(\mathrm{M}^{+\cdot+4}\right)$.

3-(2, 3-dibromo-3-(2-phenyl-1H-indol-3-yl) propanoyl)-2Hchromen-2-one(4c)

Brownish crystals, $\mathrm{MP}=222^{\circ} \mathrm{C}$, yield; $65 \%$, IR $\left(\mathrm{KBr}, \mathrm{cm}^{-1}\right) ; 3266(\mathrm{NH})$ $3100(\mathrm{Ar}-\mathrm{H}), 1698$ ( $\mathrm{C}=0$ of lactone), 1590 ( $\mathrm{C}=0$ of amide), $1110(-\mathrm{O}-)$ 698 (C-Br). ${ }^{1} \mathrm{H}$ NMR (400 MHz, $\delta$ ppm) (DMSO-d 6$), 11.4$ (s, 1H, NH), 6.9-8.0 (m, 14H, Ar-H), $5.09(\alpha-\mathrm{H})$ and $5.32(\beta-\mathrm{H})(\mathrm{d}, 2 \mathrm{H}, \mathrm{CHBr})$. Mass; $\operatorname{LCMS}(\mathrm{m} / \mathrm{z})=549(\mathrm{M}+\cdot),(\mathrm{m} / \mathrm{z})=551\left(\mathrm{M}^{++}+2\right.$ and $)(\mathrm{m} / \mathrm{z})=553\left(\mathrm{M}^{++}+4\right)$

3-(2, 3-dibromo-3-(1H-indol-3-yl)propanoyl)-2H-chromen-2one(4d)

Brownish crystals, $\mathrm{MP}=252-253{ }^{\circ} \mathrm{C}$, yield; $60 \%$, IR $\left(\mathrm{KBr}, \mathrm{cm}^{-1}\right) ; 3200$ (NH), 3040(Ar-H), 1731 ( $\mathrm{C}=0$ of lactone), 1603 (C=0 of amide), 1285 (-O-) 683(C-Br). ${ }^{1} \mathrm{H}$ NMR $(400 \mathrm{MHz}, \delta \mathrm{ppm})$ (DMSO-d $), 10$ (s, $1 \mathrm{H}, \mathrm{NH}$ ), 7.2-8.2 (m, 10H, Ar,C-H), $5.09(\alpha-\mathrm{H})$ and $5.32(\beta-\mathrm{H})(\mathrm{d}, 2 \mathrm{H}, \mathrm{CHBr})$.

3-(3-(5-chloro-2-phenyl-1H-indol-3-yl)-1-isonicotinoyl-1Hpyrazol-5-yl)-2H-chromen-2-one (5a)

Light green crystals, $\mathrm{MP}=230-231{ }^{\circ} \mathrm{C}$, yield; $50 \%$, IR $\left(\mathrm{KBr}, \mathrm{cm}^{-1} 3401\right.$ (NH), 3093(Ar-H), 1657 (C=0 of lactone), 1602 ( $\mathrm{C}=\mathrm{O}$ of amide), 1247
(-O-)and $687 \mathrm{~cm}^{-1}(\mathrm{C}-\mathrm{Cl}) .{ }^{1} \mathrm{H}$ NMR $(400 \mathrm{MHz}, \delta \mathrm{ppm}$ ) (DMSO-d 6 ), 12.3 $(\mathrm{s}, 1 \mathrm{H}, \mathrm{NH}), 6.9-8.75(\mathrm{~m}, 18 \mathrm{H}, \mathrm{Ar}-\mathrm{H})$. Mass; LCMS $(\mathrm{m} / \mathrm{z})=542.8(\mathrm{M}+\cdot)$ $(100 \%)$ and $(\mathrm{m} / \mathrm{z})=545\left(\mathrm{M}^{++}\right)(33 \%)$.

3-(1-isonicotinoyl-3-(5-methyl-2-phenyl-1H-indol-3-yl)-1Hpyrazol-5-yl)-2H-chromen-2-one (5b)

Brownish crystals, $\mathrm{MP}=196-197^{\circ} \mathrm{C}$, yield; $65 \%$, IR $\left(\mathrm{KBr}, \mathrm{cm}^{-1}\right) ; 3387$ (NH), 3030(Ar-H), 2849-2917(C-H, $\left.\mathrm{CH}_{3}\right), 1735$ ( $\mathrm{C}=0$ of lactone), 1661 (C=0 of amide), 1244 (-0-). ${ }^{1} \mathrm{H}$ NMR ( $\left.400 \mathrm{MHz}, \delta \mathrm{ppm}\right)$ (DMSO$\left.\left.\mathrm{d}^{6}\right), 12.06(\mathrm{~s}, 1 \mathrm{H}, \mathrm{NH}), 6.9-8.75(\mathrm{~m}, 18 \mathrm{H}, \mathrm{Ar}-\mathrm{H}), 2.01\left(\mathrm{~s}, 3 \mathrm{H}, \mathrm{CH}_{3}\right)\right)$ Mass; LCMS $(\mathrm{m} / \mathrm{z})=522(\mathrm{M}+\cdot)$.

3-(1-isonicotinoyl-3-(2-phenyl-1H-indol-3-yl)-1H-pyrazol-5-yl)2H-chromen-2-one(5c)

Light yellow crystals, $\mathrm{MP}=192-193{ }^{\circ} \mathrm{C}$, yield; $60 \%$, IR $\left(\mathrm{KBr}, \mathrm{cm}^{-1}\right)$; $3266(\mathrm{NH}), 3100(\mathrm{Ar}-\mathrm{H}) 1720$ ( $\mathrm{C}=0$ of lactone), 1590 (C=0 of amide) and $1110(-0-) .{ }^{1} \mathrm{H}$ NMR $(400 \mathrm{MHz}, \delta \mathrm{ppm})\left(\mathrm{DMSO}^{\mathrm{d}}{ }^{6}\right), 11.8(\mathrm{~s}, 1 \mathrm{H}$ $\mathrm{NH})$, 6.9-8.0 (m, 19H, Ar-H),). Mass; LCMS (m/z) =509(M+-).

3-(3-(1H-indol-3-yl)-1-isonicotinoyl-1H-pyrazol-5-yl)-2Hchromen-2-one(5d)

Light yellow crystals, $\mathrm{MP}=240-241^{\circ} \mathrm{C}$, yield; $70 \%$, IR $\left(\mathrm{KBr}, \mathrm{cm}^{-1}\right)$; $3220(\mathrm{NH}), 3040(\mathrm{Ar}-\mathrm{H}), 1720$ (C=0 of lactone), 1610 (C=0 of amide) and1180 $\mathrm{cm}^{-1}(-0-) .{ }^{1} \mathrm{H}$ NMR (400 MHz, $\delta \mathrm{ppm}$ ) (DMSO-d 6 ), 11.8 (s, $1 \mathrm{H}, \mathrm{NH}), 6.9-8.0(\mathrm{~m}, 15 \mathrm{H}, \mathrm{Ar}-\mathrm{H})$ ), . Mass; LCMS $(\mathrm{m} / \mathrm{z})=432(\mathrm{M}+\cdot)$.

\section{Biological evaluation}

\section{Anti-TB activity using alamar blue dye}

The anti-TB activity of compounds 5(a-d) was assessed against $M$. tuberculosis $\mathrm{H}_{37} \mathrm{Rv}$ strain (ATCC No-27294) (which was collected from MTCC, Chandigarh, Punjab) using microplate Alamar Blue MIC assay (MABA)[24]. This methodology is non-toxic, uses a thermally stable reagent and shows good correlation with proportional and BACTEC radiometric method. Briefly, $200 \mu \mathrm{l}$ of sterile deionized water was added to all outer perimeter wells of sterile 96 wells to minimized evaporation of medium in the test wells during incubation. The 96 wells plate received $100 \mu \mathrm{l}$ of the middle brook 
7H9 broth and serial dilution of compounds was made directly on plate. The final drug concentrations tested were 100 to $0.2 \mu \mathrm{g} / \mathrm{ml}$. Plates were covered and sealed with parafilm and incubated at $37{ }^{\circ} \mathrm{C}$ for five days. After five days, $25 \mu \mathrm{l}$ of freshly prepared 1:1 mixture of Almar Blue reagent and $10 \%$ tween 80 was added to the plate and incubated for 24 h. A blue color in the well was interpreted as no bacterial growth and pink color was scored as growth. The MIC was defined as lowest drug concentration which prevented the color change from blue to pink by (MIC) assay. Resources, whereby new experimental compounds can be tested for their capacity to \%, inhibit the growth of virulent $M$. tuberculosis. MIC was recorded as the lowest concentration of a compound that inhibits the growth of tested microorganism. The anti-TB activity data of test compounds were compared with the standard drugs INH, PZA, SPM and CFX which exhibited a MIC value of $0.625 \mu \mathrm{g} / \mathrm{ml}$, $3.125 \mu \mathrm{g} / \mathrm{ml}, 6.25 \mu \mathrm{g} / \mathrm{ml}$ and $3.125 \mu \mathrm{g} / \mathrm{ml}$ respectively.

\section{In silico molecular docking studies}

In order to understand binding mode and to identify the structural features of the active molecules from various indole, coumarinyl, pyridinyl and INH derivatives, we performed molecular docking studies with the mycobacterial enoyl reductase (InhA) (PDB code 4TZK). InhA (FabI/ENR) is an enoyl-ACP reductase one of the key enzymes of M. tuberculosis implicated in the biosynthesis of cell wall constituents such as mycolic acids. The Wide variety of the agents interferes with synthesis of mycolic acids, essential long a-alkylated and $\beta$-hydroxylated fatty acids found in the mycobacterial cell wall. InhA is a member of the short-chain dehydrogenase reductase superfamily of enzymes. Its attractiveness as a target for the discovery of new antibiotics has been validated some years ago. The complex X-ray crystal structures of enoyl-ACP reductase with inhibitors pyrrolidine carboxamide (PDC) for mycobacterium was retrieved from the RCSB protein data bank (http://www.rcsb.org/pdb) and used for the docking study. Molecular docking was performed with Tripos SYBYL X 2. 2.1 programs. In the previous studies of synthesis and biological evolution of 1,3,4-oxadiazole and indole-based derivatives has been reported for inhibition of mycobacterial enoyl reductase (InhA) which made a firm basis for selection of this enzyme as the potential target. The molecular docking study will act as a key indicator to understand the basis of molecular inhibition enoyl-ACP reductase activity. It also helps in the correlation of in vitro activity of various indole, coumarinyl, pyridinyl and INH derivatives.

The Computational (theoretical) predictions data from the molecular docking study were found to be in replicating the results of the experimental anti-TB activity. All the various indole, coumarinyl, pyridinyl and INH derivatives $5 a, 5 b, 5 c, 5 d$ and standards used in in vitro study were successfully docked into the active site of target enzyme mycobacterial enoylreductase (InhA/FabI/ENR) and it has observed that they have varying degrees of affinity to the active site residues. Majority of the amino acids present in the active site cavity such as glycine, alanine, leucine, isoleucine, proline, phenylalanine, tyrosine, methionine, arginine, lysine, aspartic acid and glutamic acid. These are non-polar or hydrophobic, polar charged, non-charged, negatively charged, and positively charged amino acid residues. The detail molecular interactions study in between active site amino acid residue and components of the molecule was carried out to understand the thermodynamic stability of various indole, coumarinyl, pyridinyl and INH derivatives which also provide insight information about binding modes observed within the active site cavity.

\section{Antimicrobial activity}

The newly synthesized compounds were screened for in vitro antibacterial activity against two gram-positive bacterium, Enterococcus fecalis (E. fecalis) and Staphylococcus aureus (S. aureus) and three gram-negative bacteria Escherichia coli(E. coli), Shegella and Salmonella typhi(S. typhi). In vitro antifungal activity was screened against four fungal strains, Aspergillus Oryzae(A. Oryzae), Aspergillus terreus(A. terreus), Aspergillus Nizer(A. Nizer) and Aspergillus flavus(A. flavus) [25] (Both bacterial and fungal strains were collected from the Department of Microbiology, Gulbarga University, Gulabarga). For antibacterial, preparation of nutrient broth, subculture, base layer medium, agar medium and peptone water was done as per the standard procedure. Each test compound $(5 \mathrm{mg})$ was dissolved in $5 \mathrm{ml}$ of dimethyl sulfoxide $(1000 \mu \mathrm{g} / \mathrm{ml})$. Volumes of $0.05 \mathrm{ml}$ and $0.1 \mathrm{ml}$ of each compound were used for testing. The cups each of $9 \mathrm{~mm}$ diameter were made by scooping out medium with a sterilized cork borer in a petri dish which was streaked with the organisms. The solutions of each test compound $(0.05$ and $0.1 \mathrm{ml})$ were added separately in the cups and petri dishes were subsequently incubated. Streptomycin (Std I) used as standard reference drugs $(200 \mu \mathrm{g} / \mathrm{ml})$ and dimethyl sulphoxide as a control which did not reveal any inhibition.

For antifungal, the test cultures were grown separately in sabouards dextrose broth (SDB) (Hi Media, India) at RT for $48 \mathrm{~h}$. After checking the purity, $100 \mu \mathrm{L}$ of test cultures were spread on sabouards dextrose agar plates (SDA), using cork bore $6 \mathrm{~mm}$ diameter wells were made on plates. The test compounds were dissolved in DMSO. Each well was filled with a $100 \mu \mathrm{L}$ volume of the test compound. The DMSO was used as negative control while Griscofulvin (Std II) $(1000 \mu \mathrm{g} / \mathrm{ml})$ as a positive control. Inoculated plates were kept at RT for $48 \mathrm{~h}$. Each plate was then observed for zone of inhibition. Zone of inhibition produced by each compound was measured in $\mathrm{mm}$.

\section{Antioxidant activities}

\section{Scavenging effect on stable radical 2, 2-diphenyl-1- picrylhydrazyl (DPPH)}

A rapid, simple and inexpensive method to measure the antioxidant capacity of substances involves the use of the free radical DPPH. It is widely used to test the ability of compounds to act as free radical scavengers or hydrogen donors. Antioxidants tested on DPPH were also found extremely effective in cell systems. This simple test further provides information on the ability of a compound to donate electrons during the antioxidant action. The radical scavenging mechanism is based on the transfer of acidic $\mathrm{H}$-atom from the compound to DPPH radical to form DPPH-H. The free radical scavenging activity of $4(a-d)$ and $5(a-d)$ was carried out in the presence of the stable free radical DPPH following[26-28] reported earlier by our group, using butylated hydroxyanisole(BHA) and ascorbic acid(AA) as standards. The radical scavenging activity(RSA) for methanolic solutions of 4(a-d) and 5(a-d) at concentrations 25, 50, 75 and $100 \mu \mathrm{g} / \mathrm{ml}$ containing freshly prepared DPPH solution $(0.004 \%$ $\mathrm{w} / \mathrm{v}$ ) was carried out and compared with those of standards BHA and AA. The absorbance of the solution was measured at $517 \mathrm{~nm}$ with a spectrophotometer. The RSA were expressed as the inhibition percentage and were calculated using the formula.

$$
\text { RSA (\%) }=\frac{A-B}{A} \times 100
$$

Where A is absorbance of the control and $B$ is absorbance of the compounds $4(\mathrm{a}-\mathrm{d})$ and $5(\mathrm{a}-\mathrm{d})$. The RSA of BHA and AA was also measured and compared with that of the different synthesized compounds.

\section{Total antioxidant capacity}

The total antioxidant capacity of the synthesized compounds was evaluated by the phosphomolybdenum method according to the procedure described by [26-28]. The assay is based on the reduction of $\mathrm{Mo}(\mathrm{VI})$ to $\mathrm{Mo}(\mathrm{V})$ by synthesized compounds and subsequent formation of green phosphate $/ \mathrm{Mo}(\mathrm{V})$ complex at acid pH. A $0.3 \mathrm{ml}$ of a solution of $4(\mathrm{a}-\mathrm{d})$ and $5(\mathrm{a}-\mathrm{d})$ was combined with $3 \mathrm{ml}$ of reagent solution( $0.6 \mathrm{M}$ sulfuric acid, $28 \mathrm{ml}$ sodium phosphate and $4 \mathrm{ml}$ ammonium molybdate). The absorbance of the reaction mixture was measured at $695 \mathrm{~nm}$ using a spectrophotometer against blank after cooling to room temperature. Methanol $(0.3 \mathrm{ml})$ was used as the blank. The antioxidant activity is expressed as the number of gram equivalent of ascorbic acid. The calibration curve was prepared by mixing ascorbic $(25,50,75$ and $100 \mu \mathrm{g} / \mathrm{ml})$ with methanol.

\section{Ferric reducing antioxidant power activity}

The total reducing power of the synthesized compounds was determined according to the method described [26-28]. Volumes of $25-100 \mu \mathrm{g} / \mathrm{ml}$ of different concentrations of 4 (a-d) and 5(a-d) solutions (in DMSO $1 \mathrm{ml}$ ) were mixed with phosphate buffer solution $2.5 \mathrm{ml}(0.2$ $\mathrm{M}, \mathrm{pH}=6.6)$ and $2.5 \mathrm{ml}(1 \%)$ potassium ferriccyanide $\left[\mathrm{K}_{3}\left[\mathrm{Fe}(\mathrm{CN})_{6}\right]\right]$ in 
test tubes. The mixture was placed in a water bath at $50{ }^{\circ} \mathrm{C}$ for $20 \mathrm{~min}$. Then, $2.5 \mathrm{ml}$ of $(10 \%)$ trichloroacetic acid was added to the mixture and mixed thoroughly. A volume of $2.5 \mathrm{ml}$ of this mixture was then added to $2.5 \mathrm{ml}$ of distilled water and $0.5 \mathrm{ml} \mathrm{FeCl}_{3}(0.1 \%)$ solution and allowed to stand for $10 \mathrm{~min}$. Then, the absorbance of this mixture was measured at $700 \mathrm{~nm}$ using a UV-VIS spectrophotometer, the higher the absorbance of the reaction mixture, the greater the reducing power. BHA and AA was used as a positive control.

\section{RESULTS AND DISCUSSION}

\section{Chemistry}

We report herein, a simple and expeditious synthesis various derivatives of series of 3-[3-(2,5-disubstituted-1H-indol-3-yl)-1isonicotinoyl-1H-pyrazol-5-yl]-2H-chromen-2-one 5(a-d) was achieved through the versatile and efficient synthetic route outlined in Scheme. It is apparent from the scheme that the new target molecules possess both coumarin and pyrazole units. The reaction of 3-[2,3-dibromo-3-(2,5-disubstituted-1H-indol-3-yl)propanoyl]-2Hchromen-2-one with INH seemed to be a convenient route for the synthesis of desired molecules. Starting materials 2,5-disubstituted indole-3-carboxaldehydes(1) were obtained from the Vilsmeier Haack formylation reaction of 2,5-disubstituted indoles [22] and 3acetyl-2H-chromen-2-one(2) was synthesized by the reaction of salicylaldehyde with ethyl acetoacetate in presence of catalytic amount of piperidine at room temperature following the literature procedure[23]. (E)-3-(3-(2,5-disubstituted-1H-indol-3-yl)acryloyl)$2 \mathrm{H}$-chromen-2-one $3(\mathrm{a}-\mathrm{d})$ were obtained by Claisen-Schmidt condensation of 3-acetyl-2H-chromen-2-one(2) with various 2,5disubstituted indole-3-carbaxaldehyde in presence of mixture of piperidine and n-butanol(As reported earlier by our group)[21]. Bromination of chalcones $3(\mathrm{a}-\mathrm{d})$ was carried out in chloroform using bromine in chloroform [19-21]. The resulting dibromo compounds $4(\mathrm{a}-\mathrm{d})$ on further treatment with INH in the presence of triethylamine in absolute ethanol yielded the desired compounds 3
[3-(2,5-disubstituted-1H-indol-3-yl)-1-isonicotinoyl-1H-pyrazol-5yl]-2H-chromen-2-one5(a-d).

The IR spectrum of (4a) showed absorption peaks at 3231(NH), 3032(CH), 1665(C=0, lactone), 1607(C=0, amide), 1249(-0-), 696 (C-Br) and $669 \mathrm{~cm}^{-1}(\mathrm{C}-\mathrm{Cl})$. The ${ }^{1} \mathrm{H}-\mathrm{NMR}$ spectrum of $(4 \mathrm{a})$ showed a doublet at $\delta$ 5.09 ( $\alpha$-proton) and 5.32 ( $\beta$-proton) $(2 \mathrm{H})$ due to the protons of $(\mathrm{BrCH}-$ $\mathrm{CHBr})$. A multiplet is observed in the region $\delta 7.5-8.5(\mathrm{~m}, 13 \mathrm{H}, \mathrm{Ar}-\mathrm{H})$ accounting for the aromatic protons. A singlet in the downfield at $\delta 10.7$ is observed due to indole $(\mathrm{NH})$. The mass peak $(\mathrm{m} / \mathrm{z}) 583\left(\mathrm{M}^{+}\right)$, $585\left(\mathrm{M}^{+}+2\right), 588\left(\mathrm{M}^{+}+4\right)$ and $589\left(\mathrm{M}^{++}+6\right)$ supports the formation of $(4 \mathrm{a})$. The IR spectrum of $(5 \mathrm{a})$ exhibited characteristic absorption peaks at 3401(NH), 3093(Ar, C-H) 1657(C=0,lactone), 1602(C=0,amide),1247($0-)$ and $687 \mathrm{~cm}^{-1}(\mathrm{C}-\mathrm{Cl})$. The ${ }^{1} \mathrm{H}-\mathrm{NMR}$ spectrum of $(5 \mathrm{a})$ exhibited a multiplet in the region $\delta 6.9-8.75(\mathrm{~m}, 18 \mathrm{H}, \mathrm{Ar}-\mathrm{H})$ accounting for aromatic protons. A singlet at $\delta 12.3(1 \mathrm{H})$ is attributed to the proton of indole $(\mathrm{NH})$ The mass peak $(\mathrm{m} / \mathrm{z}) 542.8\left(\mathrm{M}^{+}\right)(100 \%)$ and $544\left(\mathrm{M}^{++}\right)(33 \%)$ supports the formation of $(5 a)$.

\section{Biological evaluation}

\section{In vitro anti-TB activity}

The synthesized compounds 5(a-d) are screened for their in vitro anti-TB activity against M. tuberculosis $\mathrm{H}_{37} \mathrm{Rv}$ strain (ATCC No27294) using Alamar Blue (MABA) MIC assay at different concentrations and MIC results are given in Table1. The investigation of anti-TB screening revealed that test compounds showed varying degrees of activity against the tested microorganism. The activity of these compounds was found to be concentration dependent. Further, the compounds which showed a good activity were studied for MIC using serial dilution method to quantify the anti-TB potency of the compounds. MIC was performed at different concentrations i.e. $0.8,1.6,3.12,6.25,12.5,25$, $100 \mu \mathrm{g} / \mathrm{ml}$, and the results have been given in table 1 .

Table 1: In vitro anti-TB activity of 5(a-d)

\begin{tabular}{|c|c|c|c|c|}
\hline \multirow[t]{2}{*}{ Compounds } & \multirow[t]{2}{*}{ Concentration $(\mu \mathrm{g} / \mathrm{ml})(\mathrm{MIC})$} & \multicolumn{2}{|c|}{ Substituent } & \multirow[t]{2}{*}{ \% growth inhibition } \\
\hline & & $\mathbf{R}$ & $\mathbf{R}_{1}$ & \\
\hline $5 a$ & 50 & $\mathrm{Cl}$ & $\mathrm{Ph}$ & 80 \\
\hline $5 b$ & 25 & $\mathrm{CH}_{3}$ & $\mathrm{Ph}$ & 70 \\
\hline $5 c$ & 50 & $\mathrm{H}$ & $\mathrm{Ph}$ & 65 \\
\hline $5 d$ & 12.5 & $\mathrm{H}$ & $\mathrm{H}$ & 50 \\
\hline Isoniazide & 0.625 & - & - & \\
\hline Pyrazinamide & 3.125 & - & - & \\
\hline Streptomycin & 6.25 & - & - & \\
\hline Ciprofloxacin & 3.125 & - & - & \\
\hline
\end{tabular}

It is clear from our present findings that heterocyclic systems with electron withdrawing and donating groups on the phenyl ring of indole and the coumarin moiety play an important role in varying the efficacy of anti-TB activity. The role of electron withdrawing group in improving anti-TB activities had been reported in the literature [24]. The investigation of MIC of the tested compounds revealed that the compounds $5 \mathrm{~d}$ with No substitutions on indole ring have shown MIC at lowest concentration at $12.5 \mu \mathrm{g} / \mathrm{ml}, 5 \mathrm{~b}$ have shown MIC at $25 \mu \mathrm{g} / \mathrm{ml}$ and compounds $5 \mathrm{a}$ and $5 \mathrm{c}$ exhibited moderate activity at MIC value $50 \mu \mathrm{g} / \mathrm{ml}$ against tested M. tuberculosis $\mathrm{H}_{37} \mathrm{Rv}$ strain as compared with the standard INH, PZA, STM and CFX. To compare the binding affinity of the newly synthesized compounds, they were subjected for molecular docking using Tripos SYBYL X 2. 2.1 programs. The newly synthesized compounds $5 \mathrm{a}, 5 \mathrm{~b}, 5 \mathrm{c}$ and $5 \mathrm{~d}$ were analyzed for their mechanism of anti-TB action. To represent the details of docking score following terms is used as total score as total docking score, crash score as degree of inappropriate penetration by the ligand into the protein and of interpenetration between ligand atoms that are separated by rotatable bonds of compounds and polar score gives an idea about the contribution of the polar non-hydrogen bonding interactions to the total score is shown in table 2 . The value of total score (inhibition constant-log (ki)) provides an indication of how potent an inhibitor is higher the value for total score (inhibition constant-log (ki)), more is the potency of inhibitor.

Table 2: Molecular docking and biological activity of compounds 5a-5d and standards

\begin{tabular}{lllll}
\hline Compounds & Concentration $(\boldsymbol{\mu g} / \mathbf{m l})(\mathbf{M I C})$ & Total score (-logki) & Crash score & Polar score \\
\hline 5a & 50 & 6.484 & -1.2445 & 1.629 \\
5b & 25 & 6.9202 & -1.4637 & 1.0192 \\
5c & 50 & 6.302 & -0.8327 & 0.9686 \\
5d & 12.5 & 6.9297 & -1.3002 & 0.9621 \\
INH & 0.625 & 3.7045 & -0.2817 & 1.2368 \\
Pyrazinamide & 3.125 & 3.0024 & -0.1673 & 1.0652 \\
Streptomycin & 6.25 & 5.0524 & -4.2486 & 3.9264 \\
Ciprofloxacin & 3.125 & 6.6764 & -0.9356 & 5.5809 \\
\hline
\end{tabular}

Total score: Total docking score: Crash: degree of inappropriate penetration by the ligand into the protein and of interpenetration between ligand atoms that are separated by rotatable bonds; Polar: contribution of the polar non-hydrogen bonding interactions to the total score. 
The total score which indication of how much the potent an inhibitor is very high for molecule $5 \mathrm{~d}$ which indicate that it is most active molecules among the four docked molecules. The compound binds and inhibits with a total docking score of 6.193 , crash score of1.8239 which indicate the degree of inappropriate penetration by the ligand into the protein and of interpenetration between ligand atoms that are separated by rotatable bonds and a polar score of 1.5839 contributions of the polar non-hydrogen bonding interactions to the total score.

The detailed analysis of the binding interactions and binding pose of $5 \mathrm{~d}$ showed that it is stabilized within the active site of InhA through an extensive network of favourable non-covalent interactions such as conventional hydrogen bond interaction, Pi interaction, Pi-PiT shaped interaction, alkyl interaction, and Pi-Alkyl interactions. The aliphatic active site amino acid gly96 interact with the indole ring nitrogen atom to forms conventional hydrogen bond with a distance of $1.81 \AA$. Polar amino acid met155 interact non-covalently with benzopyranone phenyl ring of distance $5.62 \AA$ to form Pi-Sulfur interaction. The active site amino acid residues such as Ala198, Ile16, Ile95, Ile215, Ala157, Phe243 and MET199, form Pi-Pi Tshaped stacked, amide Pi-stacked, alkyl and Pi-Alkyl interactions with Indole, benzopyranone phenyl and phenyl ring with various distance shown in fig. $1 \mathrm{a}$.

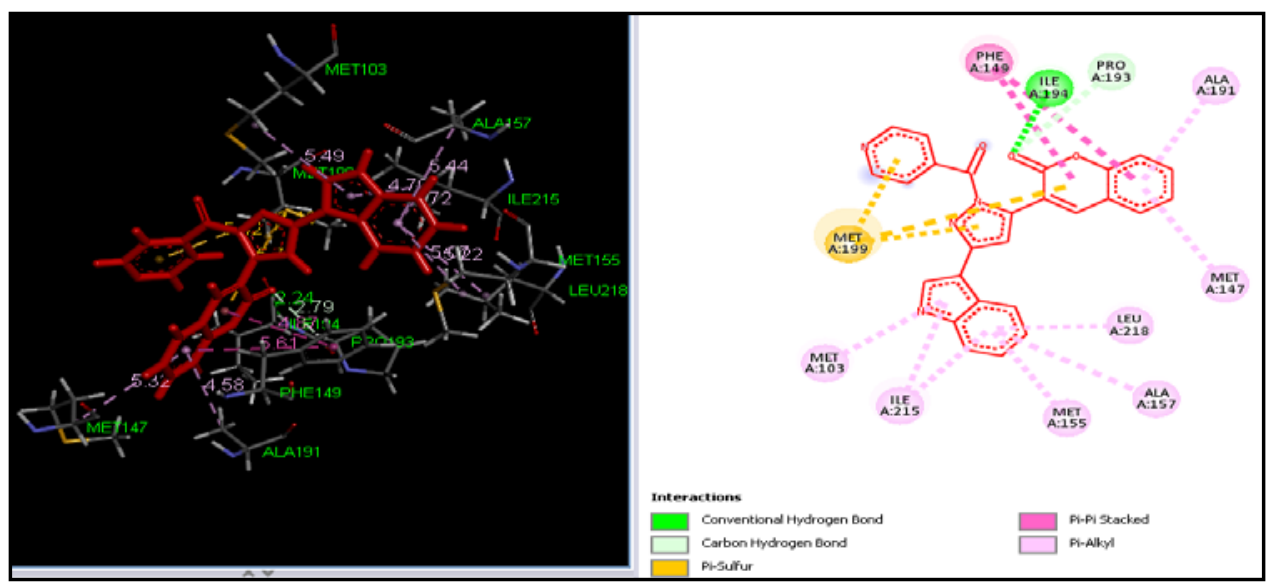

Fig. 1a: Binding pose and molecular interactions of $5 \mathrm{~d}$ into the active site of enoyl reductase

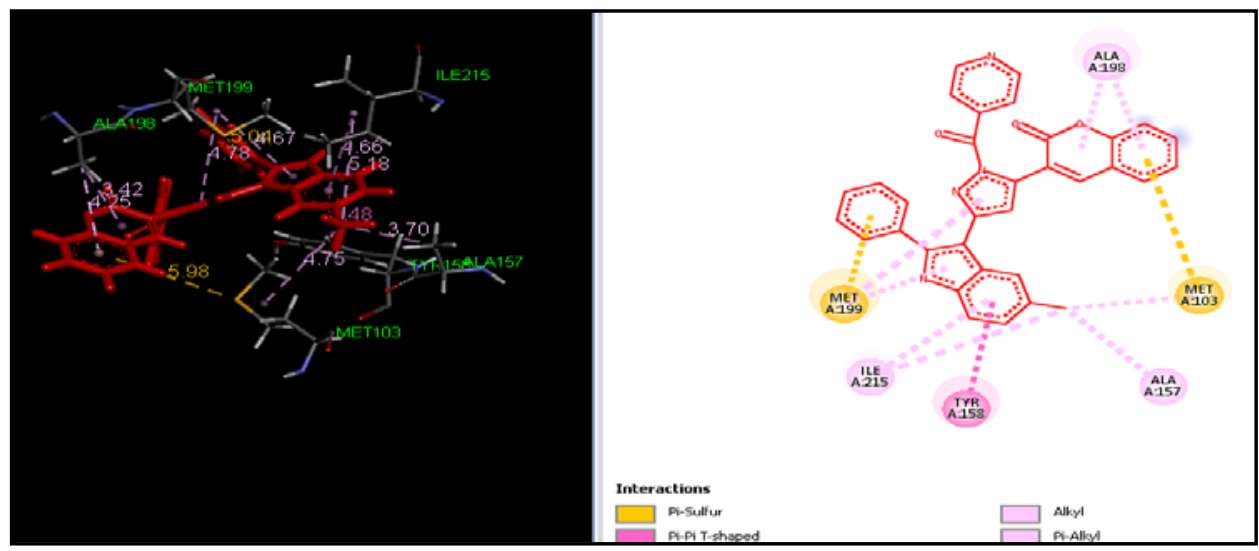

Fig. 1b: Binding pose and molecular interactions of $5 b$ into the active site of enoyl reductase

The pyrazole derivatives $5 \mathrm{~b}$ also showed very good total docking score, crash score and polar score 6.0668,-2.6964 and 1.4776 respectively give an idea about its high potency. Analysis of molecular/binding interactions and binding poses gives an information about how it occupy in the active site of target enzyme mycobacterial enoyl reductase and it from only Pi interactions. Polar amino acids Met103 interact with indole ring $\mathrm{Cl}$ atom with distance $5.08 \AA$ and it also interacts with phenyl ring of indole of distance $5.06 \AA$. Another polar amino acid Met199 interact with benzopyrole phenyl and coumarine ring of distance 4.51 and $4.58 \AA \AA$ respectively. Active site amino acids such as Leu207, Ile202 and Ile215 forms Pialkyl and alkyl of various distances shown in fig. 1b. Molecular docking study and analysis of $5 \mathrm{~d}$ and $5 \mathrm{~b}$ compounds revealed that presence of a similar binding mode and binding interactions as observed for $5 \mathrm{~d}, 5 \mathrm{~b}$ and standards such as INH, PZA, STM and CFX but among them $5 \mathrm{~d}$ is most active and others are moderately potent derivatives of pyrazole derivatives having coumarins and indole nucleus. Observational analysis and theoretical predication of molecular docking study shown that various basic features of synthesized compounds and pharmacophore scaffolds have potential to inhibit survival of $M$. tuberculosis, may act as potential leads in anti-TB drug discovery.

\section{In vitro antimicrobial activity}

The results of antibacterial activities revealed that the majority of the synthesized compounds showed varying degree of inhibition against tested microorganisms. Compared with the standard streptomycin, the antibacterial potency of compounds (4d) was found to be the highest against $S$. typhi and S. aureus and (5d) with E. coli and Shegella (table 3). According to the Structure-Activity Relationship (SAR), it is clear that initially, key scaffold (4d) showed the considerable activity due to the presence of electron withdrawing bromo group.

Further, the introduction of INH moieties influences for effective increases in the activity. Among the synthesized compounds with hydrogen substituents on phenyl ring of indole core is more active than the other analogues as reported earlier by our group [29-30]. The reason would be more lipophilic nature of indole moiety along with 
the presence of electronegative groups like halogens [32]. The antifungal screening revealed that some of the tested compounds showed good inhibition against various tested fungal strains (table 3). Initially, key intermediates (4d) showed considerable activity. Further, the introduction of INH moieties accounted for the enhanced activity. It is to be noted that the hydrogen substituent present on the phenyl ring of indole was found to have the strongest influence on the activity and this was confirmed by the fact that the presence of electron withdrawing bromo group in compounds (4d and 5c) displayed excellent activity than the standard Griscofulvin. Compounds (4a), (4c), (5a) and (5c) have also exhibited good activity because of chloro and hydrogen functional group at $C-5$ position on the phenyl ring of indole. From the studies, the analogues holding electron donating methyl group were not demanded for enhanced activity against all bacterial strains. This might be the reason for decreases the activity in compounds (4b) and (5b) compared to other analogues.

It is concluded antifungal investigation demonstrated that the halogen and hydrogen substituents were the source for the significant increases in the activity as reported earlier by our group [29-30].

Table 3: In vitro antimicrobial results

\begin{tabular}{|c|c|c|c|c|c|c|c|c|c|c|}
\hline \multirow[t]{3}{*}{ Compounds } & \multirow{3}{*}{$\begin{array}{l}\text { Concentration } \\
(\mu \mathrm{g} / \mathrm{ml})\end{array}$} & \multicolumn{9}{|c|}{ Zone of inhibition in $\mathrm{mm}($ mean \pm SD) } \\
\hline & & \multicolumn{5}{|c|}{ Antibacterial activities } & \multicolumn{4}{|c|}{ Antifungal activities } \\
\hline & & E. coli & E. fecalis & Shegella & S. aureus & S. typhi & A. Oryzae & A. terreus & A. Nizer & A. flavus \\
\hline \multirow[t]{3}{*}{$4 a$} & 25 & $5.8 \pm 0.28$ & - & - & - & $06 \pm 0.5$ & - & - & - & $-=$ \\
\hline & 50 & $08 \pm 0.57$ & $5.6 \pm 0.57$ & $6.3 \pm 0.57$ & $6.3 \pm 0.57$ & $8.6 \pm 0.57$ & $5.3 \pm 0.57$ & $8.6 \pm 0.57$ & $10.1 \pm 0.28$ & $10 \pm 0.5$ \\
\hline & 100 & $12.3 \pm 0.28$ & $8.8 \pm 0.28$ & $8.6 \pm 0.28$ & $8.6 \pm 0.28$ & $10 \pm 0.28$ & $10.5 \pm 0.5$ & $10.6 \pm 0.57$ & $11.6 \pm 0.57$ & $11.5 \pm 0.28$ \\
\hline \multirow[t]{3}{*}{$4 \mathrm{~b}$} & 25 & - & $8.3 \pm 0.57$ & - & - & $5.3 \pm 0.57$ & - & - & - & - \\
\hline & 50 & $10.1 \pm 0.28$ & $11.1 \pm 0.35$ & $8.6 \pm 0.28$ & - & $8.6 \pm 0.57$ & $7.5 \pm 0.5$ & $5.3 \pm 0.57$ & $8.3 \pm 0.57$ & - \\
\hline & 100 & $10.5 \pm 0.5$ & $12.5 \pm 0.5$ & $12 \pm 0.5$ & $8.1 \pm 0.28$ & $12 \pm 0.50$ & $11 \pm 0.50$ & $10.3 \pm 0.57$ & $10.6 \pm 0.57$ & $7.6 \pm 0.57$ \\
\hline \multirow[t]{3}{*}{$4 c$} & 25 & $5.3 \pm 0.57$ & $3.8 \pm 0.76$ & - & - & - & - & $8.3 \pm 0.57$ & - & $9 \pm 0.16$ \\
\hline & 50 & $8.5 \pm 0.57$ & $8.3 \pm 0.57$ & - & $5.6 \pm 0.57$ & - & $8.6 \pm 0.57$ & $10.6 \pm 0.57$ & $10.3 \pm 0.57$ & $10.8 \pm 0.28$ \\
\hline & 100 & $10.6 \pm 0.57$ & $8.3 \pm 0.28$ & $7.1 \pm 0.28$ & $8.5 \pm 0.57$ & $7.6 \pm 0.57$ & $10.6 \pm 0.57$ & $11.6 \pm 0.57$ & $13 \pm 0.16$ & $11.5 \pm 0.5$ \\
\hline \multirow[t]{3}{*}{$4 d$} & 25 & - & $5.9 \pm 0.5$ & $8.6 \pm 0.57$ & $8.6 \pm 0.02$ & $9.8 \pm 0.28$ & - & $5.3 \pm 0.57$ & $4.5 \pm 0.5$ & - \\
\hline & 50 & $8.3 \pm 0.57$ & $09 \pm 0.23$ & $10.3 \pm 0.57$ & $11.1 \pm 0.28$ & $11.5 \pm 0.5$ & $8.6 \pm 0.57$ & $8.6 \pm 0.57$ & $8.6 \pm 0.57$ & - \\
\hline & 100 & $10.8 \pm 0.28$ & $12.5 \pm 0.5$ & $13.1 \pm 0.28$ & $13.8 \pm 0.28$ & $13.6 \pm 0.57$ & $11.1 \pm 0.28$ & $11.6 \pm 0.57$ & $10.8 \pm 0.57$ & $08 \pm 0.28$ \\
\hline \multirow[t]{3}{*}{$5 a$} & 25 & - & - & - & - & - & $5.6 \pm 0.57$ & - & $8 \pm 0.28$ & - \\
\hline & 50 & $5.3 \pm 0.57$ & $7.8 \pm 0.28$ & $5.8 \pm 0.76$ & $3.69 \pm 0.57$ & $06 \pm 0.28$ & $8.8 \pm 0.28$ & $8.3 \pm 0.57$ & $11 \pm 1$ & $10.6 \pm 0.28$ \\
\hline & 100 & $6.6 \pm 0.57$ & $7.9 \pm 0.11$ & $9.1 \pm 0.28$ & $13 \pm 0.5$ & $8.6 \pm 0.57$ & $10.6 \pm 0.28$ & $10.5 \pm 0.5$ & $14 \pm 1$ & $12.8 \pm 0.76$ \\
\hline \multirow[t]{3}{*}{$5 b$} & 25 & - & - & - & - & - & - & - & $8.1 \pm 0.28$ & $8.6 \pm 0.57$ \\
\hline & 50 & $6 \pm 0.28$ & $3.64 \pm 0.57$ & $5 \pm 0.5$ & $8.2 \pm 0.46$ & $5.3 \pm 0.57$ & $5.6 \pm 0.57$ & $5.6 \pm 0.28$ & $8.3 \pm 0.57$ & $11.6 \pm 0.57$ \\
\hline & 100 & $9.3 \pm 0.57$ & $8.7 \pm 0.25$ & $10.1 \pm 0.28$ & $10.1 \pm 0.28$ & $12.5 \pm 0.5$ & $8.6 \pm 0.57$ & $10.3 \pm 0.28$ & $11.3 \pm 0.57$ & $12.6 \pm 0.57$ \\
\hline \multirow[t]{3}{*}{$5 c$} & 25 & - & - & - & - & - & $8.1 \pm 0.28$ & $4.1 \pm 0.28$ & $08 \pm 1$ & $8.3 \pm 0.57$ \\
\hline & 50 & $5.5 \pm 0.5$ & $5.3 \pm 0.57$ & $5.1 \pm 0.28$ & $5.5 \pm 0.5$ & $5.3 \pm 0.57$ & $10.1 \pm 0.28$ & $10.6 \pm 0.57$ & $11.3 \pm 0.5$ & $12.3 \pm 0.57$ \\
\hline & 100 & $10.5 \pm 0.57$ & $7.1 \pm 0.28$ & $8.6 \pm 0.28$ & $8.5 \pm 0.5$ & $10.3 \pm 0.28$ & $10.6 \pm 0.28$ & $11.6 \pm 0.57$ & $13.3 \pm 0.57$ & $13 \pm 1$ \\
\hline \multirow[t]{3}{*}{$5 d$} & 25 & - & - & - & - & - & - & - & - & $3.3 \pm 0.57$ \\
\hline & 50 & $5.3 \pm 0.57$ & $5.5 \pm 0.5$ & $5.5 \pm 0.5$ & $5.1 \pm 0.28$ & $5.3 \pm 0.57$ & $8.3 \pm 0.57$ & $8.1 \pm 0.28$ & $8.8 \pm 0.57$ & $9.3 \pm 0.57$ \\
\hline & 100 & $13 \pm 0.28$ & $12.1 \pm 0.28$ & $13.1 \pm 0.28$ & $13.5 \pm 0.5$ & $12.6 \pm 0.28$ & $10.6 \pm 0.28$ & $10.5 \pm 0.5$ & $10.3 \pm 0.57$ & $11.3 \pm 0.57$ \\
\hline \multirow[t]{3}{*}{ Std I } & 25 & $10 \pm 0.28$ & $11 \pm 0.28$ & $12 \pm 0.28$ & $11 \pm 0.28$ & $12 \pm 0.28$ & - & - & - & - \\
\hline & 50 & $12 \pm 0.28$ & $12 \pm 0.28$ & $13 \pm 0.28$ & $12 \pm 0.28$ & $13 \pm 0.28$ & - & - & - & - \\
\hline & 100 & $13 \pm 0.28$ & $14 \pm 0.28$ & $15 \pm 0.28$ & $14 \pm 0.28$ & $16 \pm 0.28$ & - & - & - & - \\
\hline \multirow[t]{3}{*}{ Std II } & 25 & - & - & - & - & - & $10 \pm 0.28$ & $11 \pm 0.28$ & $12 \pm 0.28$ & $11 \pm 0.28$ \\
\hline & 50 & - & - & - & - & - & $11 \pm 0.28$ & $12 \pm 0.28$ & $13 \pm 0.28$ & $13 \pm 0.28$ \\
\hline & 100 & - & - & - & - & - & $12 \pm 0.28$ & $14 \pm 0.28$ & $15 \pm 0.28$ & $14 \pm 0.28$ \\
\hline
\end{tabular}

Each value represents mean \pm SD (n=3), '-' Not shown any zone of inhibition, Escherichia coli(E. coli), Enterococcus fecalis(E. fecalis), Staphylococcus aureus(S. aureus),Shegella, Salmonella typhi(S. typhi), Aspergillus Oryzae(A. Oryzae), Aspergillus terreus(A. terreus), Aspergillus Nizer(A. Nizer) and Aspergillus flavus(A. flavus).

\section{Scavenging effect on stable radical 2, 2-diphenyl-1-picryl-} hydrazyl (DPPH)

The newly synthesized compounds were tested for DPPH free RSA with (BHA) and (AA) as standards and the absorbance of synthesized compounds are given in fig. 2. The investigation of DPPH radical scavenging activity revealed that compounds with-Cl and-H (4d, 5a and 5c) have exhibited excellent RSA at 25, 75 and 100 $\mu \mathrm{g} / \mathrm{ml}$ respectively, as reported earlier by our group [29-30].

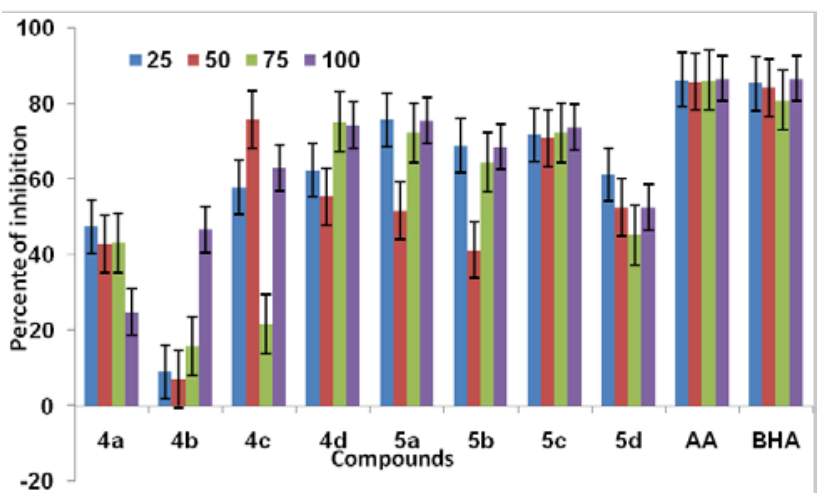

Fig. 2: Free radical scavenging activities of synthesized compounds 


\section{Total antioxidant capacity}

The total antioxidant capacity of the synthesized compounds was evaluated by the phosphomolybdenum method. The antioxidant activity is expressed as the number of gram equivalent of ascorbic acid. The absorbance of synthesized compounds as shown in fig. 3. The investigation of total antioxidant capacity of the synthesized compounds revealed that compounds with- $\mathrm{Cl}-\mathrm{CH}_{3}$ and- $\mathrm{H}(4 \mathrm{~d}, 5 \mathrm{a}$ and $5 \mathrm{~b})$ have exhibited excellent total antioxidant capacity activity at 25, 75 and 100 $\mu \mathrm{g} / \mathrm{ml}$ respectively as reported earlier by our group [29-30].

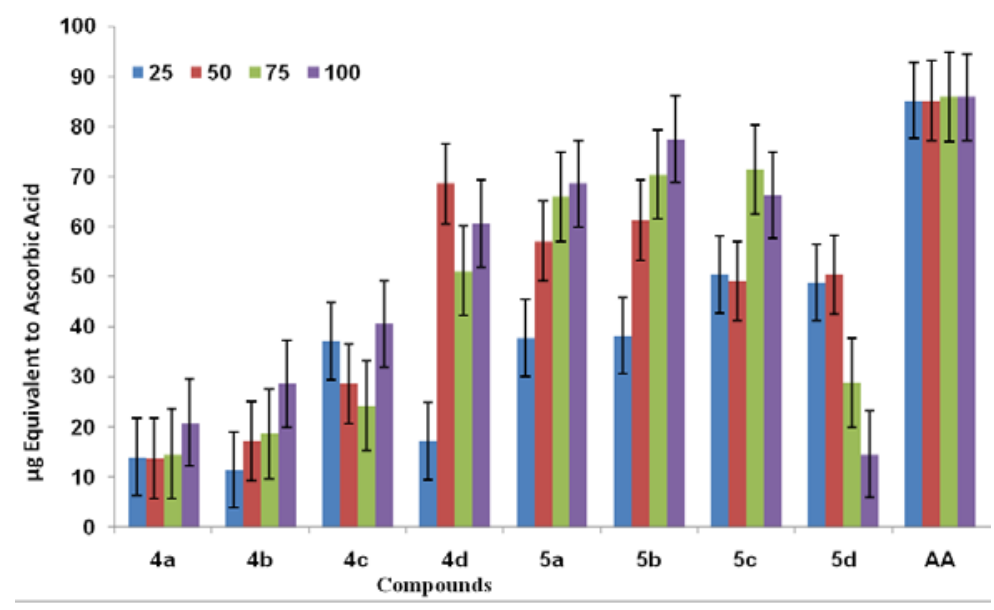

Fig. 3: Total antioxidant capacity of synthesized compounds

\section{Ferric reducing antioxidant power activity}

The total reducing power of the synthesized compounds was determined according to the method. (BHA) and (AA) was used as a positive control. The ferric reducing antioxidant power activity is expressed as the reductive ability. The absorbance of synthesized compounds as shown in fig. 4. The investigation of ferric reducing the antioxidant power of the synthesized compounds revealed that compounds with- $\mathrm{Cl},-\mathrm{CH}_{3}$ and- $\mathrm{H}$ ( $4 \mathrm{~d}$ $5 a, 5 b$ and $5 d$ ) have displayed excellent ferric reducing antioxidant power at 25,75 and $100 \mu \mathrm{g} / \mathrm{ml}$ respectively as reported earlier by our group [29-30].

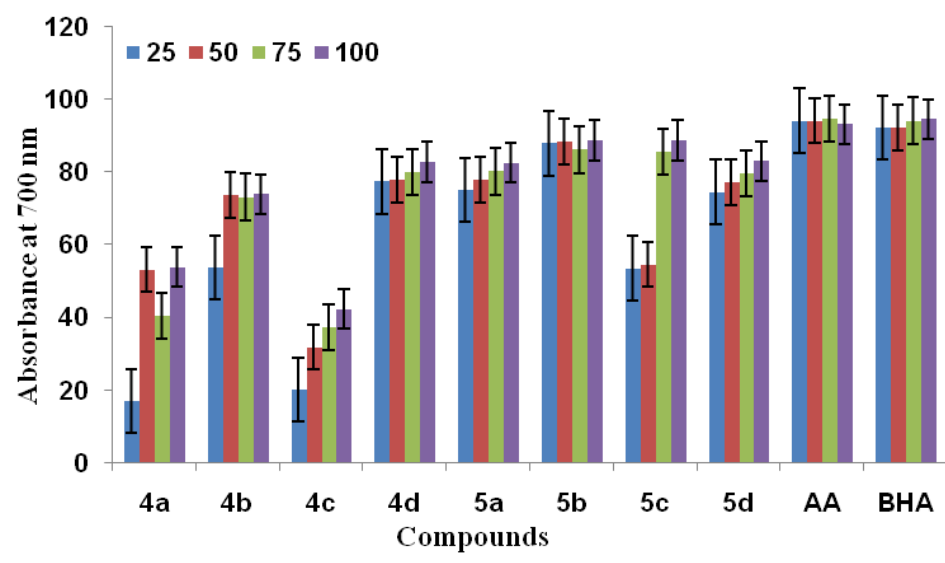

Fig. 4: Ferric reducing antioxidant power activity of synthesized compounds

\section{CONCLUSION}

In conclusion, we have designed an efficient synthetic route for the synthesis of some novel biologically active pyrazole moiety linked to coumarins and indole substitutions like chloro, methyl and hydrogen. Compounds $5(\mathrm{a}-\mathrm{d})$ have exhibited promising anti-TB activities. The antimicrobial results revealed that the compounds $4(\mathrm{a}-\mathrm{d})$ and $5(\mathrm{a}-\mathrm{d})$ containing the halogen or hydrogen substituent's on the phenyl ring of indole exhibited potent antimicrobial and antioxidant activities. This observation suggests that di-substitution in the target compounds by halogens enhanced the anti-TB, antimicrobial and antioxidant activities.

\section{ACKNOWLEDGEMENT}

Authors are thankful to Chairman, Department of Chemistry, Gulbarga University, Kalaburagi for providing necessary facilities to carry out this research work. The authors sincerely acknowledge UGC-BSR, No. F.25-
1/2013-14 (BSR)/N0. F.7-226/2009 (BSR) dated 19th Nov 2014, New Delhi (India) for financial support. We sincerely express our gratitude to Dr. Kishore G. Bhat, MD, (Microbiology) Maratha Mandal's NGH Institute of Dental Sciences and Research Centre, Belgaum for anti-TB activities. We are grateful to Dr. J. N. Sangshetti Associate Prof Y. B. Chavan College of Pharmacy, Aurangabad for molecular docking studies.

\section{CONFLICT OF INTERESTS}

Declared none

\section{REFERENCES}

1. Collins FM. Mycobacterial disease, immune suppression and acquired immunodeficiency syndrome. Clin Microbiol Rev 1989;2:360-77.

2. Graham NM, Galai KE, Nelson J. Effect of isoniazid chemoprophylaxis on the HIV-related mycobacterial disease. Arch Intern Med 1996;156:889-94 
3. Halsey NA, Coberly JS, Desormeaux J, Losikoff P. Randomised trial of isoniazid versus rifampicin and pyrazinamide for prevention of tuberculosis in HIV-1 infection. Lancet 1998; 351:786-92.

4. Inderlied CB, Kemper CA, Bermudez LE. The mycobacterium avium complex. Clin Microbiol Rev 1993;6:266-10.

5. Telzak EE, Sepkowitz K, Alpert P. Multidrug-resistant tuberculosis in patients without HIV infection. N Engl J Med 1995;333:907-11.

6. Dessen AA, Quemard JS, Blanchard WR, Sacchettini JC. Crystal structure and function of the isoniazid target of M. tuberculosis. Science 1995;267:1638-41.

7. Morris S, Bai GH, Suffys P, Portilo-Gomez L. Molecular mechanisms of multiple drug resistance in clinical isolates of Mycobacterium tuberculosis. J Infect Dis 1995;171:954-60.

8. Mandell GL, Petri WA. Antimicrobial agents used in the chemotherapy of tuberculosis. In: Hardman J. eds. Goodman and Gilman's the pharmacological basis of therapeutics. $9^{\text {th }}$ edn. McGraw-Hill, New York; 1996. p. 1155-74.

9. Sensi P, Grassi G. Antimycobacterial agents. In: Wolff ME. Ed. Burger's medicinal chemistry and drug discovery. $5^{\text {th }}$ edn Wiley, New York; 1996. p. 575-35.

10. Kucukguzel SG, Rollas S. Synthesis, characterization and pharmacological properties of some 4 arylhydrazono-2pyrazoline-5-one derivatives obtained from heterocyclic amines. Eur J Med Chem 2000;35:761-5.

11. Nauduri D, Reddy GB. Antibacterials and antimycotics. Part 1. Synthesis and activity of 2 pyrazoline derivatives. Chem Pharm Bull 1998;46:1254-7.

12. Ali MA, Shaharyar M, Siddiqui AA. Synthesis, structural activity relationship and anti-tubercular activity of novel pyrazoline derivatives. Eur J Med Chem 2007;42:268-75.

13. Shaharyar M, Siddiqui AA, Ali MA. Synthesis and in vitro antimycobacterial activity of N1-nicotinoyl-3-(40-hydroxy-30methyl phenyl)-5-[(sub)phenyl]-2-pyrazolines. Bioorg Med Chem Lett 2006a;16:3947-52.

14. Shaharyar M, Siddiqui AA, Ali MA. Synthesis and evaluation of phenoxy acetic acid derivatives as an anti-mycobacterial agent. Bioorg Med Chem Lett 2006b;16:4571-8.

15. Genin MJ, Allwine DA, Anderson DJ. Substituent effects on the antibacterial activity of nitrogen-carbon-linked (azolylphenyl) oxazolidinones with expanded activity against the fastidious gram-negative organisms $\mathrm{H}$. influenzae and $\mathrm{M}$. catarrhalis. J Med Chem 2000;43:953-70.

16. Kucukguzel SG, Rollas S. Synthesis, characterization of novel coupling products and 4 arylhydrazono-2-pyrazoline-5-ones as potential antimycobacterial agents. IL Farmaco 2002;57:583-7.

17. Shenoy GG, Bhat AR, Bhat GV, Kotian M. Synthesis of pyrazoles and isoxazole in triethanolamine medium. Indian J Heterocycl Chem 2001;10:197-9.
18. Kopec AE, Zwolska Z. Bioavailability factors of INH in fast and slow acetylators, healthy volunteers. Acta Poloniae Pharm 2002;59:452-7.

19. Aragade, Mahesh P, Pradeepkumar R. Coumarinyl pyrazole derivatives of INH: promising antimycobacterial agents. Med Chem Res 2013;22:2279-83.

20. Aragade P, Maddi V, Khode S. Synthesis and antibacterial activity of new series of 3-[3(substituted phenyl)-1isonicotinoyl-1H-pyrazol-5-yl]-2H-chromen-2-one derivatives. Arch Pharm Chem Life Sci 2009;342:361-6.

21. Doddappa A, Biradar JS. Synthesis of novel substituted pyrazolines and isoxazolines containing indole and coumarines. Heterocycl Commun 2009;6:411-16.

22. Biradar JS. Studies in the indole field. Ph. D. Thesis, Gulbarga University; 1982.

23. Knoevenagel E. Condensationn zwischen malonester und aldehyden unter dem einfluss von ammoniak und organischen aminen. Chem Ber 1898;31:2596.

24. Maria CS, Lourenco, Marcus V, deSouza N. Evaluation of antitubercular activity of nicotinic and isoniazid analogues. ARKIVOC 2007;15:181-91.

25. Godipurge SS, Yallappa S, Biradar NJ, Biradara JS. A facile and green strategy for the synthesis of $\mathrm{Au}, \mathrm{Ag}$ and $\mathrm{Au}-\mathrm{Ag}$ alloy nanoparticles using aerial parts of R. hypocrateriformis extract and their biological evaluation. Enzyme Microbial Technol 2016;95:174-84.

26. Biradar JS, Sashidhar BS, Parveen R. Synthesis, antioxidant and DNA cleavage activities of novel indole derivatives. Eur J Med Chem 2010;45:4074-8.

27. Godipurge SS, Rahber S, Biradar JS, Mahurkar N. Evaluation of pharmacological activities of Rivea hypocrateriformis in experimental animal models. Inter J Toxicol Pharmacol Res 2015;7:65-73.

28. Godipurge SS, Biradar NJ, Biradar JS, Mahurkar N. Chemical composition and hepatoprotective effects of polyphenolic fraction from Rivea hypocrateriformis in paracetamol-induced liver damage in wistar albino rats. Int J Pharm Pharm Sci 2016;8:228-34.

29. Biradar JS, Sashidhar BS. Design and synthesis of some nove thiophene analogues of indole as a potent antimicrobial and antioxidant agents. Org Chem 2010;4:280-3.

30. Biradar JS, Sashidhar BS, Parveen R. Synthesis, antioxidant and DNA cleavage activities of novel indole derivatives. Eur J Med Chem 2010;45:4074-8.

31. Biradar JS, Sasidhar BS. Solvent-free, microwave assisted Knoevenagel condensation of novel 2, 5-disubstituted indole analogues and their biological evaluation. Eur J Med Chem 2011;46:6112-8.

32. Javarappa R, Nagaraja N. Synthesis and screening of benzofuran fused $C$-2,4,6-substituted pyrimidine derivatives as a new antibacterial and antifungal agent. Int J Pharm Pharm Sci 2017;9:27-32. 